\title{
Trends in diabetes incidence from 1992 to 2015 and projections for 2024: A Portuguese General Practitioner's Network study
}

Article · June 2016

DOI: $10.1016 /$ j.pcd.2016.05.003

READS

48

8 authors, including:

Mafalda Sousa-Uva

National Institute of Health Dr. Ricardo Jor..

28 PUBLICATIONS 34 CITATIONS

SEE PROFILE

\section{Rogerio T Ribeiro}

APDP - Diabetes Portugal

26 PUBLICATIONS 198 CITATIONS

SEE PROFILE

\section{Baltazar Nunes}

National Institute of Health Dr. Ricardo Jorge

151 PUBLICATIONS 896 CITATIONS

SEE PROFILE

Carlos Matias Dias

New University of Lisbon

104 PUBLICATIONS 585 CITATIONS

SEE PROFILE 


\title{
Original research
}

\section{Trends in diabetes incidence from 1992 to 2015 and projections for 2024: A Portuguese General Practitioner's Network study}

\author{
Mafalda de Sousa-Uva ${ }^{a, *}$, L. Antunes ${ }^{a}$, B. Nunes ${ }^{a, b}$, A.P. Rodrigues ${ }^{a}$, \\ J.A. Simões ${ }^{c, d}$, R.T. Ribeiro ${ }^{e, f}$, J.M. Boavida ${ }^{g}$, C. Matias-Dias ${ }^{a, b}$ \\ a National Health Institute Doutor Ricardo Jorge, Lisbon, Portugal \\ ${ }^{b}$ National School of Public Health, New University of Lisbon, Lisbon, Portugal \\ c Unidade de Saúde Familiar Marquês de Marialva, Cantanhede, Portugal \\ d Faculty of Health Sciences, University of Beira Interior, Covilhã, Portugal \\ e APDP Diabetes Portugal, Education and Research Center (APDP-ERC), Lisbon, Portugal \\ ${ }^{f}$ CEDOC, Chronic Diseases Research Center, NOVA Medical School, Lisbon, Portugal \\ g Portuguese Diabetes Programme, Directorate General of Health, Lisbon, Portugal
}

\section{A R T I C L E I N F O}

Article history:

Received 4 February 2016

Received in revised form

26 April 2016

Accepted 13 May 2016

Available online $\mathrm{xxx}$

Keywords:

Diabetes

Incidence

Projections

Portugal

Epidemiology

\begin{abstract}
A B S T R A C T
Background: Diabetes is known as a major cause of morbidity and mortality worldwide. Portugal is known as the European country with the highest prevalence of this disease. While diabetes prevalence data is updated annually in Portugal, the General Practitioner's (GP) Sentinel Network represents the only data source on diabetes incidence. This study describes the trends in Diabetes incidence, between 1992 and 2015, and estimate projections for the future incidence rates in Portugal until 2024.

Methods: An ecological time-series study was conducted using data from GP Sentinel Network between 1992 and 2015. Family doctors reported all new cases of Diabetes in their patients' lists. Annual trends were estimated through Poisson regression models as well as the future incidence rates (until 2024), sex and age group stratified. Incidence rate projections were adjusted to the distribution of the resident Portuguese population given Statistics Portugal projections.

Results: The average increase in Diabetes incidence rate was in total 4.29\% (CI95\% 3.80-4.80) per year under study. Until 1998-2000, the annual incidence rate was higher in women, and from 1998-2000 to 2013-2015 turn out to be higher in men. The incidence rate projected for 2022-2024 was $972.77 / 10^{5}$ inhabitants in total, and $846.74 / 10^{5}$ and $1114.42 / 10^{5}$, respectively, in women and men.

Conclusions: This is the first study in Portugal to estimate diabetes incidence rate projections. The disturbing reported projections seem realistic if things continue as in the past. Actually, effective public health policies will need to be undertaken to minimize this alarming future scenario.
\end{abstract}

(c) 2016 Primary Care Diabetes Europe. Published by Elsevier Ltd. All rights reserved.

\footnotetext{
* Corresponding author.

E-mail address: mafalda.uva@insa.min-saude.pt (M. de Sousa-Uva).

http://dx.doi.org/10.1016/j.pcd.2016.05.003

1751-9918/@ 2016 Primary Care Diabetes Europe. Published by Elsevier Ltd. All rights reserved.
} 


\section{Introduction}

Diabetes Mellitus (DM) is a chronic disease characterized by high levels of blood glucose, that develops either from the destruction of insulin-producing cells (type 1 diabetes) or when body tissues become resistant to the action of insulin, even in a state of circulating hyperinsulinemia (type 2 diabetes) [1]. Type $1 \mathrm{DM}$ is an auto-immune condition that usually develops in childhood or adolescence, while type 2 DM develops in adulthood and is associated with obesity, physical inactivity and unhealthy diet. The latter represents $90 \%$ of the global cases of diabetes [2,3].

DM is known as a major cause of morbidity and mortality worldwide, being one of the main responsible for the global burden of disease [4] It is the leading cause of blindness, kidney failure and amputation worldwide [5], and is responsible for causing cardiovascular problems that lead to $50-80 \%$ of deaths in people with diabetes [6]. The prevalence of DM in Portugal in 2014 was estimated at 13.1\% (10.8\% in women and $15.8 \%$ in men) [7] and Portugal is known as the European Union country with the highest prevalence of this chronic disease [8].

While prevalence data is updated annually, based on the 2010 PREVADIAB nationwide study [9], and taking into consideration demographic changes, diabetes incidence has garnered less attention as a health indicator. The General Practitioner's (GP) Sentinel Network (GP Sentinel Network) represents, in Portugal, the only data source on diabetes incidence, since 1992 to nowadays.

Thus, this study aimed to gain insight into the DM incidence trends, between 1992 and 2015, in the Portuguese population under observation of the GP Sentinel Network, as well as to make projections for the future incidence rates based on this knowledge.

\section{Methods}

GP Sentinel Network is a network based on the volunteer work of General Practice/Family Medicine doctors whose professional activity is developed in primary healthcare centers of the Portuguese National Health System. These doctors report several health events, agreed each year. Between 1992 and 2015 (except 2001 and 2002), family doctors from GP Sentinel Network reported all new cases of DM (both types 1 and 2) in their patients' lists. Diabetes case definition used was based on Directorate-General of Health (DGS) guidelines for clinical practice [10]. From 1992 to 1995 the GP Sentinel Network covered only Portuguese mainland, but since 1996 and 1997 Madeira and Azores (Portuguese islands) began, respectively, participation in the network.

An ecological time-series study was conducted using data from the GP Network between 1992 and 2015, with exception of the years 2001 and 2002.

Every year GP's update the composition of their patients' lists, taking into account some users characteristics such as age and gender, which represent variables also considered in this study.
The annual DM incidence rates were calculated dividing the observed number of new cases by the population under effective observation from the GP Network during the years under study. The population under effective observation (PUEO) is the annual average of the GP's patients' list weekly sum: $\mathrm{PUEO}_{t}=\sum_{m=1}^{M} N_{m} I_{t m}$, where $N_{m}$ is the number of patients composing the GP $m$ list; and $I_{t m}$ is a variable that takes the value 1 if the doctor $m$ was active in week $t$, and 0 otherwise. They were only considered the patients' lists from the GP's who were active on each week (which means those that reported cases, even if they were of zero). The population under effective observation used as the denominator for the annual incidence rate is the average of the PUEO in the 52 weeks of the year, namely: $\mathrm{PUEO}_{\text {year }}=\sum_{\mathrm{t}=1}^{\mathrm{T}} \mathrm{PUEO}_{\mathrm{t}} / 52$. The population under effective observation varied between 231,292 in 1991 and 37,363 in 2015. The incidence rate estimates are presented per 100,000 inhabitants, per triennium, and disaggregated by sex and age group. The triennium 2001-2003 have only data for 2003, since the new cases of diabetes were not reported by the GP network in the years 2001 and 2002.

Poisson regression models were used to estimate the annual trends from 1992 to 2015. The observed incidence rates were then adjusted for the Portuguese population distribution, according to estimates from the Statistics Portugal [11]. The incidence rate projections from 2015 to 2024, sex and age group stratified, were also estimated using Poisson Regression models as proposed by Hakulinen and Dyba [12]. Incidence rate projections were then adjusted to the resident Portuguese population distribution given the Statistics Portugal projections [13]. Prediction intervals for the projected rates were calculated based on the work of Dyba and Hakulinen [14]. Pearson goodness of fit statistic and residual analysis were used to assess the goodness of the fitted models.

\section{Results}

\subsection{Total and sex stratified incidence}

In the first triennium under study, 1992-1994, the annual incidence rate was $261.7 / 10^{5}$ inhabitants, and in the last triennium, 2013-2015, was 630.42/105 inhabitants (Fig. 1). Until 1998-2000, the annual incidence rate was higher in women, and from 1998-2000 to 2013-2015 turn out to be higher in men (Fig. 1).

The average increase in DM incidence rate was $4.29 \%$ (CI95\% 3.80-4.80) per year under study. In men the annual trend was also of increase (5.16\% [CI95\% 4.47-5.86]) as well as in women, although slighter for the latter (4.29\% [CI95\% 3.80-4.80]).

\subsection{Total and sex stratified projected incidence}

The incidence rate projected for 2022-2024 was $972.77 / 10^{5}$ inhabitants in total (CI95\% 864.05/10 $\left.-1081.49 / 10^{5}\right)$, and $846.74 / 10^{5}$ (CI95\% 707.98/10 $\left.-985.49 / 10^{5}\right)$ and $1114.42 / 10^{5}$ (CI95\% 944.13/10 $\left.-1284.72 / 10^{5}\right)$, respectively, in women and men (Fig. 1). 


\section{Diabetes incidence rate between 1992-2015 and projections until 2024}

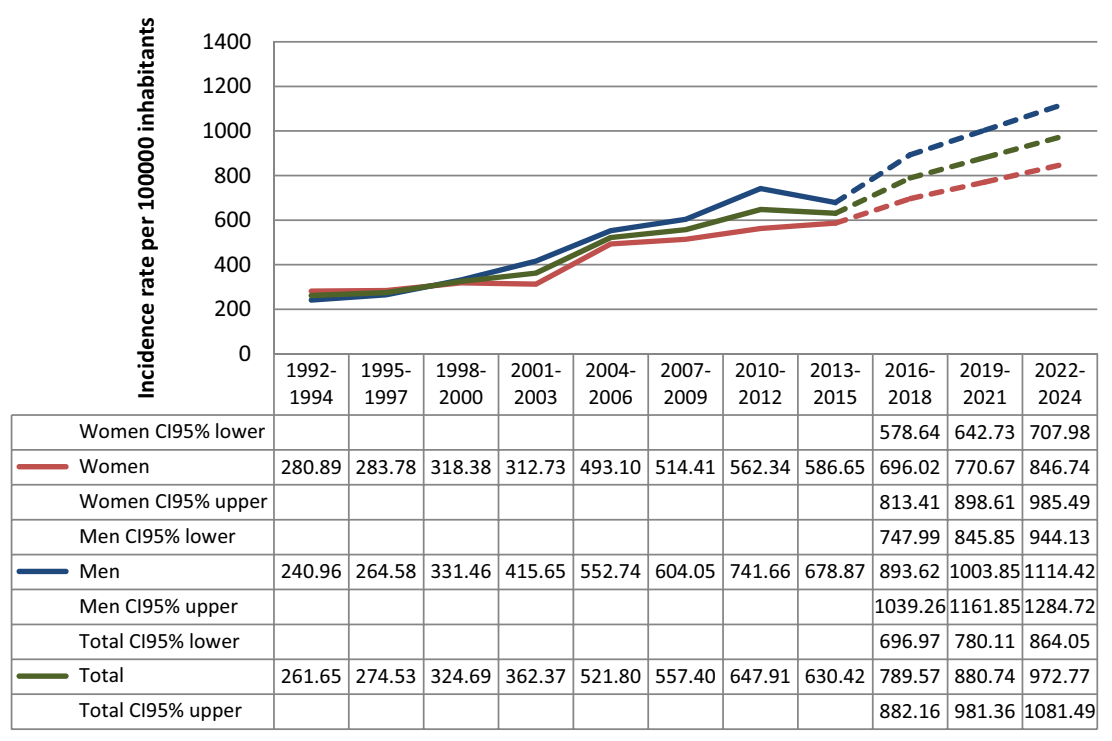

Fig. 1 - Diabetes Mellitus annual incidence rate progression in the population under observation from GP Sentinel Network and projections for 2024, sex stratified.

\subsection{Age stratified incidence}

As expected, there were observed greater DM incidence rate estimates in the oldest age groups. Generally, in men the age group with a greater incidence rate was the 55-64 years old (Fig. 2) and in women it was the 65-74 years old age group (Fig. 3).

There was a significant annual increase in DM incidence rate in the age groups above the 55 years old. The greater increase was seen in men in the $75+$ age group $(7.05 \%$ per year [IC95\% 5.52-8.60]).

\subsection{Age stratified projected incidence}

The higher incidence rate projected for 2022-2024 was, in women, in the age group 65-74 years old (1730.06/10 inhabitants [CI95\% 1430.56-2029.56]) and, in men, in the age group 55-64 years old $\left(2412.22 / 10^{5}\right.$ inhabitants [CI95\% 1569.47-3254.97]) (Figs. 2 and 3).

\section{Discussion}

There was an increasing trend in the DM incidence in the time period under study, from 1992 to 2015 . We propose that this increase can be related with three main possible reasons that could be acting jointly or individually. On one hand, it could be associated with an increase in the prevalence of obesity in Portugal [15], as obesity is known in the literature as one of the main risk factors for type 2 diabetes [5]. On the other hand, it could also be related with the increasingly pronounced population aging, since the estimates of the DM incidence in this study are higher at older ages and there is evidence that the overall DM increases with age [16]. Finally, it could also be associated with the changing in Diabetes diagnosis criteria, in 2002, which eventually could justify a higher number of diagnosed cases in recent years [17]. Following the known distribution of diabetes new cases by age group, we expect that type 2 diabetes represent the largest number of the observed diabetes cases reported here by the GP sentinel network, and thus also of the projected rates.

The inversion of diabetes incidence estimates among men and women, until 1998-2000 higher in females, and after that time period higher in males, it is as far as we know not described in the national literature, although already described in the international literature [18]. However, it seems consistent with available prevalence data, where men are more affected by diabetes than women [7]. Such an event may be associated with an increase in the disease diagnosis in men due to the increased demand for health care in recent years by this group. On the other hand, may be due to positive changes in eating behaviors more pronounced in women in the last years $[8,19]$. It could be even because of a greater frequency of obesity in recent years in men [8].

In what concerns DM incidence rate projections, based on the most likely scenario, we projected that the number of new cases of individuals with diagnosed diabetes in Portugal will be $972.77 / 10^{5}$ habitants by $2022-2024$. The fitted model actually produced estimates which seemed similar to those observed.

This is the first study in Portugal that estimates projections for diabetes incidence, so we have no term of comparison nationally. However, our results seem reasonable when compared to the United States (U.S.) population whose incidence projections are from $800 / 10^{5}$ habitants in 2008 to $1500 / 10^{5}$ habitants in 2050 [20].

The increase in diabetes incidence projected here could be largely attributable to two major demographic factors, similar to those pointed by Boyle and colleagues [20]: (1) Portuguese population aging; and (2) increasing size of higher risk groups.

Furthermore, the projections we report suffer from several limitations, such as not being able to discern between type 1 and type 2 diabetes. Other relevant limitations include not 


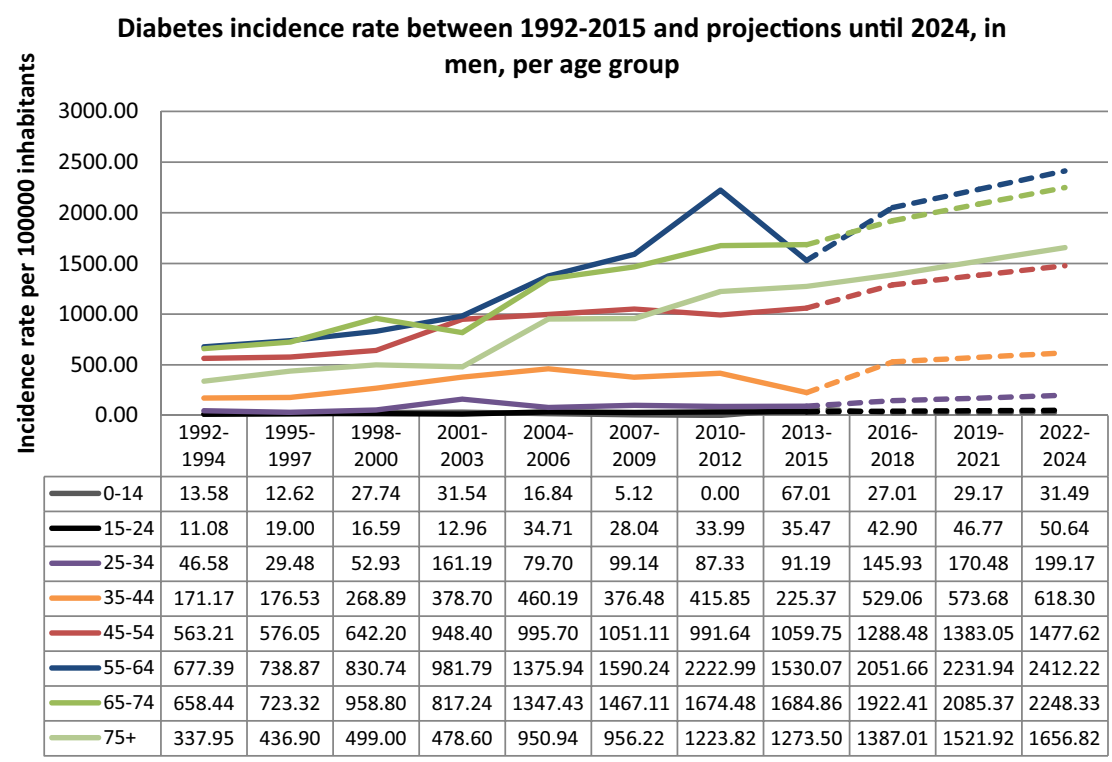

Fig. 2 - Men Diabetes Mellitus annual incidence rate progression in the population under observation from GP Sentinel Network and projections for 2024, age group stratified.

taking into consideration possible effects of local initiatives concerning diabetes prevention in Portugal and the drop in the population under effective observation from the GP Sentinel Network since 1992 to nowadays. Both these limitations may, eventually, reduce the projected diabetes incidence rates. The drop in the population under effective observation could be associated with new tasks attributed to GPs medical specialty in the last few years in Portugal, which could gave them less time to notify the new cases of disease in their patient lists. This is in fact the reason pointed out by the largest number of GPs who left the network. On the other hand, simultaneously, the primary care system has been recently restructured in Portugal, which could also explain some dissatisfaction with the working conditions. Additionally, many of the doctors who were part of the GPs network when it was created are now passing through a retirement process. This drop in the population under effective observation could eventually be responsible for a reduction in the projected diabetes incidence rates, because the GPs who remained in the GP Sentinel Network could be those particularly interested in the reported diseases. The other GPs who left the network, could not have reported as well in older years, since they did not have so much attention and interest in the health problems under study and in the GP network. If this "less motivated GPs" continued in the sentinel network, it should be observed eventually lower incidence rates, which could result in a decrease

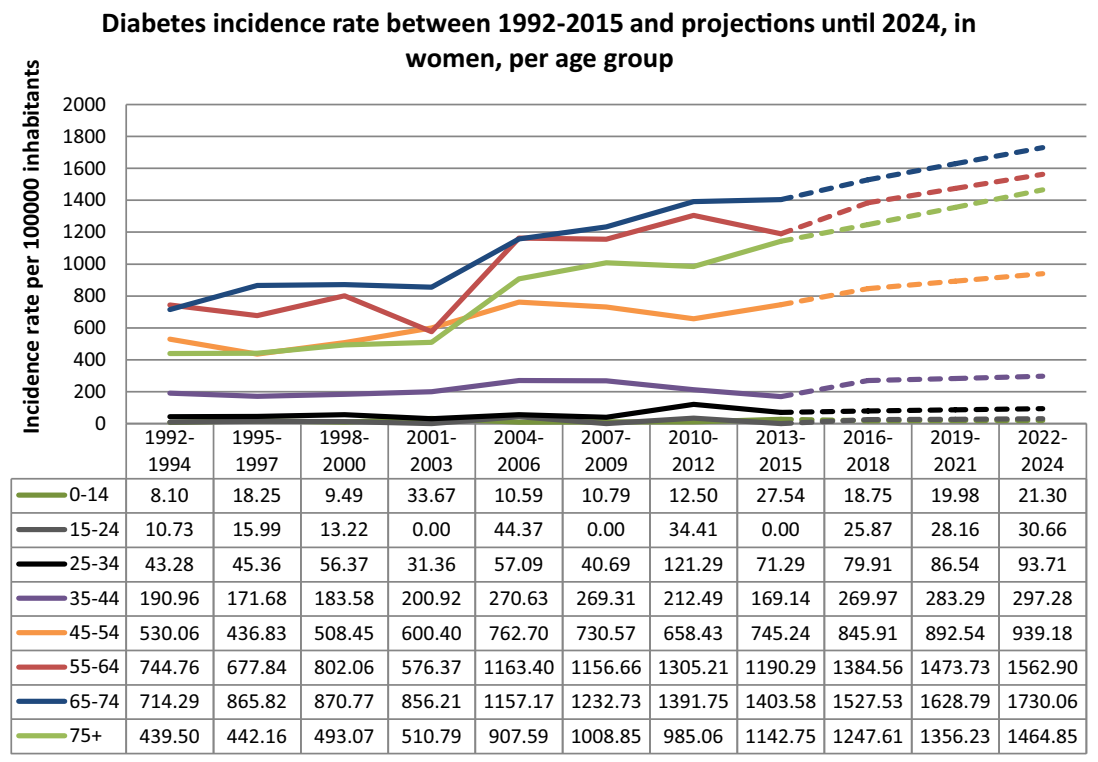

Fig. 3 - Women Diabetes Mellitus annual incidence rate progression in the population under observation from GP Sentinel Network and projections for 2024, age group stratified. 
of the projections here reported. Quite the opposite, unforeseen increases in life expectancy or the implementation of further diabetes screening actions may increase the number of newly diagnosed diabetes cases. Also, changes in diagnostic criteria could affect incidence rates, as well as the increased or decreased access to medical care.

We have assumed a linear increase in diabetes incidence like Boyle et al., 2001 [21]. However, diabetes incidence seemed to rise differently until 2003 and after this time period. Should the rise in diabetes incidence rates be nonlinear, our projections may be overestimated. Nonetheless, we argue that the generalized linear model used is a consistent and widely used method useful for a first approach to this subject in Portugal giving the GPs Sentinel Network data set $[12,14]$.

Finally, it should be noticed that the disturbing reported projections seem realistic if the circumstances continue as in the past, with no major Public Health changes occurring concerning diabetes. For an instance, the projected increase of older people with diabetes underlines the need for a better support of social and healthcare services in this age group.

Effective Public Health policies will need to be undertaken to minimize this alarming future scenario. Actually, this study could give some support for Public Health goals design in order to minimize the impact of diabetes in the Portuguese population in future years.

\section{Conflict of interest}

The authors declare no conflicts of interest.

\section{Acknowledgments}

The authors thank the volunteer work of General Practice/Family Medicine doctors from the GP Sentinel Network who provided information about incident cases of diabetes in their patients' lists.

\section{REFERENCES}

[1] WHO, Diabetes Programme, WHO, Switzerland, Geneva, 2013, Available at http://www.who.int/diabetes/action. online/basics/en/index.html.

[2] WHO, Global Status Report on NCDs 2010, WHO, Switzerland, Geneva, 2011, Available at http://www.who. int/nmh/publications/ncd_r eport2010/en/.

[3] International Diabetes Federation, IDF Diabetes Atlas, Brussels, Belgium, 2014. Available at http://www.diabetesatlas.org/.

[4] WHO, Causes of Death 2008: Data Sources and Methods, WHO, Switzerland, Geneva, 2011, Available at http://www.who.int/healthinfo/global_burden_disease/ cod_2008_sources_methods.pdf.

[5] A.D. Deshpande, M. Harris-Hayes, M. Schootman, Epidemiology of diabetes and diabetes-related complications, Phys. Ther. 88 (2008) 1254-1264.
[6] E. Gakidou, L. Mallinger, J. Abbott-Klafter, R. Guerrero, S. Villalpando, R.L. Ridaura, et al., Management of diabetes and associate cardiovascular risk factors in seven countries; a comparison of data from national health examination surveys, Bull. World Health Org. 89 (2011) 172-183.

[7] L. Gardete-Correia, et al., Diabetes Factos e Números, Observatório Nacional da Diabetes, Portugal, Lisboa, 2015, Available at https://www.dgs.pt/estatisticas-de-saude/ estatisticas-de-saude/publicacoes/diabetes-factos-enumeros-7-edicao.aspx.

[8] International Diabetes Federation, 2015 Diabetes Atlas, International Diabetes Federation, Belgium, Brussels, 2015, Available at http://www.diabetesatlas.org/ resources/2015-atlas.html.

[9] L. Gardete-Correia, J.M. Boavida, J.F. Raposo, A.C. Mesquita, C. Fona, R. Carvalho, et al., First diabetes prevalence study in Portugal: PREVADIAB study, Diabetic Med. 27 (2010) 879-881.

[10] Sociedade Portuguesa de Diabetologia, Normas da DGS, Sociedade Portuguesa de Diabetologia, Portugal, Lisboa. Available at http://www.spd.pt/index.php/normas-da-dgs.

[11] Statistics Portugal, Dados estatísticos, Statistics Portugal, Lisboa, 2013, Available at http://www.ine.pt/xportal/ xmain?xpid=INE\&xpgid=ine_base_dados.

[12] T. Hakulinen, T. Dyba, Precision of incidence predictions based on poisson distributed observations, Statist. Med. 13 (1994) 1513-1523.

[13] Statistics Portugal, Projections from 2008 to 2060, Statistics Portugal, Lisbon, 2009, Available at https://www.ine.pt/ xportal/xmain?PUBLICACOESmodo=2\& PUBLICACOESpub boui=65946767\&xpgid=ine_publicacoes \&xpid=INE.

[14] T. Dyba, T. Hakulinen, Comparison of different approaches to incidence prediction based on simple interpolation techniques, Statist. Med. 19 (2000) 1741-1752.

[15] I. Carmo, O. Santos, J. Camolas, J. Vieira, M. Carreira, L. Medina, L. Reis, J. Myatt, A. Galvão-Teles, Overweight and obesity in Portugal: national prevalence in 2003-2005, Obes. Rev. 9 (2008) 11-19.

[16] F. Soriguer, A. Goday, A. Bosch-Comas, E. Bordiú, A. Calle-Pascual, R. Carmena, et al., Prevalence of diabetes mellitus and impaired glucose regulation in Spain: the Di@bet.es Study, Diabetologia 55 (2012) 88-93.

[17] DGS, Actualização dos Critérios de Classificação e Diagnóstico da Diabetes Mellitus, DGS, Portugal, Lisboa, 2002, Available at http://www.dgs.pt/upload/membro.id/ ficheiros/i005604.pdf.

[18] S. Wild, G. Roglic, A. Green, R. Sicree, H. King, Global prevalence of diabetes. Estimates for the year 2000 and projections for 2030, Diabetes Care 27 (2004) 1047-1053.

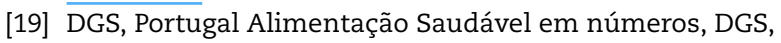
Portugal, Lisboa, 2014, Available at https://www.dgs.pt/ estatisticas-de-saude/estatisticas-de-saude/publicacoes/ portugal-alimentacao-saudavel-em-numeros-2014.aspx.

[20] J.P. Boyle, T.J. Thompson, E.W. Gregg, L.E. Barker, D.F. Williamson, Projection of the year 2050 burden of diabetes in the US adult population: dynamic modeling of incidence, mortality, and prediabetes prevalence, Popul. Health Met. 8 (2010) 1-12.

[21] J.P. Boyle, A.A. Honeycutt, K.M. Narayan, T.J. Hoerger, L.S. Geiss, H. Chen, et al., Projection of diabetes burden through 2050: impact of changing demography and disease prevalence in the U.S., Diabetes Care 24 (2001) 1936-1940. 